\title{
A pragmatic view on the financial theories
}

\author{
Mihai CHIȘU \\ The Bucharest University of Economic Studies, Faculty of International Business and \\ Economics, Bucharest, Romania \\ chisu_mihai@yahoo.com
}

\begin{abstract}
This presentation reviews some real examples from a trading daily basis behavior proving the sentiment is one of the most important drivers when it comes to investment decision. During decades of studying and observing the financial markets we have seen different approaches in the light of many prestigious writers. Are we rational enough to be good candidates for Fama's theory of Efficient Market Hypothesis? Is it true what John Maynard Keynes stated 90 years ago when he said "the market is subject to waves of optimistic and pessimistic sentiment"? Is the financial behavior the new trend in the financial markets? Are Daniel Kahneman (Nobel Prize winner 2002) and Amos Tversky the new challengers in the market theories league? Future research should concentrate on various symptoms of sentiment and what makes investors become prone to sentiment. This is an important issue to be debated since investors constantly have to analyze, process and interpret huge data of information which provides the basis for their actions.
\end{abstract}

Keywords: behavioral finance, capital markets, anomalies, bubbles, market sentiment, financial theories, Romanian capital market, market volatility, market crush, BET-FI Index.

\section{Introduction}

When it comes to the capital markets, the experience has all the time a leading role. Theory creates the proper environment to securely explore ideas, but positive results are obtained by hard work into the pragmatic area.

The purpose of the majority of the investors is to understand the market by developing a sixth sense which can guide them throughout the vicious world of capital markets (Baker, Nofsinger, 2010). Starting from this idea we may categorize the investors considering the knowledge, investment duration and risk as mainly criteria of different typologies as it follows:

Table 1. Investors' categories

\begin{tabular}{|l|l|l|}
\hline Knowledge & Investment duration & $\begin{array}{l}\text { Risk and profit } \\
\text { expectancies }\end{array}$ \\
\hline Beginner & Short - a few days to a few moths & Low risk - small profit \\
\hline Moderate & Medium - a few months to a couple of years & Medium risk - medium profit \\
\hline Expert & Long - more than two years & High risk - big return \\
\hline
\end{tabular}

Combining these three criteria we observe that a beginner (low experienced profile investor) will make medium to long term investments with a low to medium risk. Getting more experienced will allow the investors to approach riskier placements, the duration will be medium to short this time and the return is aimed to be bigger since the risk is considerable. In the last category we find speculators, that type of investors less concerned with the fundamental value of a share or asset, but more focus on price movements and news capable to affect prices (Zaloom, 2007). If the first category follows fundamentals (EBITDA, EV/EBITDA, PER, P/BV, net profit, dividends, pay-out ratios etc.) the speculator will scout the market to find any news and intercept any 
feeling that negatively or positively could affect the market, reason to take profit of any price movements that can occur respectively.

\section{Different approaches of financial markets. Literature review}

Same investors based on their level of experience will be able to interpret the market with more or less complexity (Diermeier et al., 1984). Even if in normal conditions the access to more information is not all the time beneficial for an investor because of the high effort of sort and analyze it, successful investors are very rigorous in order at this chapter and follow some thumb rules.

In most cases all start from a macro view. If the macro environment is in line with the investor's expecting, the next step is to select the economic area/areas which mostly benefits/benefit in this proper macro environment. Obviously, the final answer is given after applying a S.W.O.T. analysis to the main companies in the selected sector. The S.W.O.T. analysis will identify these facts starting from a fundamental point of view, nevertheless considering three key factors as relevant for a good selection of stocks:

1. Profit of placement meaning the selected company has or will have a profitable path in economic terms. To cash dividends and record capital gain is the main interest of any investor.

2. Safety of the investment is crucial because it balance the risk with the reward. The investors should select companies based on the idea of continuity of the existence of them. Any worries about this aspect should be enough to reconsider the opportunity of that placement.

3. Liquidity of the selected stock, even if this is not a major preoccupation for the common investors, could become a real problem if not well managed. The existence or not of the liquidity can be the main difference between real money and paper money. In other words, until an investor doesn't cash out his position he is only a happy owner of a nice portfolio on paper.

Experienced investors after a rigorous study of the markets (macro -> economic area -> company fundamentals and particular market characteristics) usually try to figure the market sentiment through a final approach, the technical analysis research (Reilly, Brown, 2012). This last one action is meant to identify the right moment of entering the market after observing volumes, patterns, oscillators, trends etc.

The fundamental analysis starts from the financial statements of a company and explores data about assets, liabilities, earnings, revenues, expenses etc. (Helfert, 2001). These figures create the possibility to make comparison among similar companies, to identify which one is more profitable and efficient for the long term. The fundamental analysis is known as quantitative analysis as well and assumes to observe the competitors and the markets besides all financial aspects of a company. Fundamental analysis seeks to detect differences between market value and the intrinsic value of an action by studying earnings, profits, projections on dividends and risks associated with the company, assets and liabilities. The profit to be achieved comes from trading the difference between the market prince and the fair basic price, the operation being close when recognizes the "mistake” of interpretation and will re-evaluate the action at the fair price (Bodie, Kane, Marcus, 2014).

Fundamental analysis is based on a number of prerequisites:

- $\quad$ The company will work in the future

- $\quad$ The company has an intrinsic value

- $\quad$ This value can be determined based on company data - Company accounting

- $\quad$ Taxes which they have to pay in the next period; 
- $\quad$ The quality of the employees, of the management staff.

- Fundamental analysis attempts to determine a value as close as possible to reality on the basis of information about the company's financial statements, the

field in which it operates, the investments made, the assets held etc.

Fundamental analysis of a company involves analyzing financial data from the company, its solvency, its competitive and executive advantages, as well as its competitors. The result of this study is to evaluate the success or failure of a company in PICBE | 199 the economic environment, as well as the way in which its actions will be influenced (Abarbanell, Bushee, 1997).

As described before, one last step necessary to fulfill the procedure for a profitable transaction is to identify the right moment in the short-term frame. This chapter belongs to the technical analysis. All started more than 100 years ago when Charles Dow and Edward Jones founded Dow Jones \& Company. Dow theory assumes the capital markets evolve in trends which reflect the investors' sentiment for short, medium and long terms. A positive trend is characterized by higher highs and higher lows, a negative one occurs when the prices make lower highs and lower lows (Glickstein, Wubbels, 1983). From these simple observations and a permanent need to predict better entering/exiting moments in the market a whole industry has been created. Lots of prestigious economists have created since then lots of theories, indices, oscillators, patterns etc. trying to put on the table more and more relevant and useful instruments to help in the wise investment process. Technical analysis is a form of study of shares by anticipating their evolution based on the study of past financial data, prices and volumes. The technical analysis is the evaluation and the attempt to predict the future trends based on the past evolution of prices. The prices are drawn on the graphs and make different shapes and configurations. According to technical analysts, these configurations are repeated regularly and lead to similar market behaviors.

\section{Technical analysis - a tool for market participants. Methodology.}

Technical analysis is a tool for predicting the future course of financial markets based on past price movements. Like weather forecasts, technical analysis does not provide certainty about the future - but it helps market participants anticipate what is likely to change in price dynamics.

One of the most appreciated technical analyst of all times is John Murphy and his well-known creation Technical analysis of the financial markets (1999) has the following main assumptions which will be milestone for future generations of chartists:

- $\quad$ The main sources of information available to technical analysts are price, volume and open interest;

- $\quad$ Market evolution includes all the information;

- $\quad$ Prices are moving in trend;

- $\quad$ History repeats itself.

Following the Dow theory this domain of technical analysis was deeply explore and develop in the coming decades, lots of technical theories giving more and more hope that the financial markets' secret could be decipher (decoded) and the continuous effort to reach the philosopher's stone of the markets can be finally achieved. Elliott wave's theory, Wolfes waves, Gann's levels and squares, Jenkins JTTL lines and pitchfork analysis are just a few of many theories who have created huge bases of data, graphs and technical instruments for passionate investors.

As the markets have evolved and the information was more and more accessible, lots of non-believers of these theories have started to emerge and put pressure on the 
capability of the new theories to be real useful instruments of predictions. Here are some of the most popular disagrees of ones of the most representatives and successful investors:

- $\quad$ Peter Lynch: „Charts are great for predicting the past.”

- Warren Buffett: „I realized technical analysis didn't work when I turned the charts upside down and did not get a different answer."

- Warren Buffett: „If past history was all there was to the game, the richest people PICBE | 200 would be librarians."

- Benoit Mandelbrot: „Everybody knows that everybody else knows about the support points, so they place their bets accordingly."

With adepts on both sides, pros and cons, the technical analysis approach remains and will remain a useful instrument to identify a proper level of the market when there is a better chance of winning and getting a better result for an investment.

Let's go back in time now and find out where these theories about economics has started from (Schumpeter, 2006). More than 2,500 years ago the first known figure interested to explore this area was the ancient Greek Hesiod ( $\sim 750 \mathrm{BC})$ who made first statements about economics in general. The list continues with other ancient philosophers of the Greco-Roman world, goes further in the Middle Ages represented by Thomas Aquinas (who wrote the thesis Summa Theologica sharing his ideas about the concept of a just price) and Nicolaus Copernicus who studied the quantity theory of money. The roots of the modern economy were established by Adam Smith (1723-1790) seen as the father of modern political economy. In his master piece The Wealth of Nations Smith (1998) explains for the first time that demand, supply and competition are the elements that control as an „invisible hand” the economic market and bring order into a system that at first looks chaotic and unguided by any law.

Another prominent figure whose ideas are nowadays discussed especially after the financial crisis of 2008 is John Keynes (1883-1946) who is an adept of state intervention in the economy to correct economic cycles. Keynes advocated the use of fiscal and monetary policies to mitigate the adverse effects of economic recessions and depressions. Keynes' main work is The General Theory of Employment, Interest and Money, published in 1936 (Keynes, 2008).

A new theory has emerged in 1965 when the economist Eugene Fama published his work The Behavior of Stock Market Prices proposing the Efficient Market Hypothesis which states that prices reflect objectively all the existing information (Fama, 1965). In the 20th century the capital markets became more and more attractive, reason for lots of economist to focus on price evaluation and risk. In this respect we must emphasize the extraordinary and inspirational work of William Sharpe who developed the Capital Asset Pricing Model, the first model to describe the relationship between expected return and systematic risk for assets and stocks (Sharpe, 1964). The list continues with Harry Markowitz who successfully proposed the Modern Portfolio Theory according to who risk and reward go together in finance describing how risk-adverse investors can construct portfolios in order to optimize or maximize expected returns based on a given level of market risk (Markowitz, 1991). The capital markets have evolved creating more and more complex financial instruments, a good environment for the economists Fisher Black, Robert Merton and Myron Scholes to propose a mathematical model containing derivative investment instruments known as Black-Scholes formula. The model evaluates an option by taking into account the strike price, time to expiration and the volatility of the share, not actually knowing the final price of the underlaying share at the expiration. 
In the last decades more and more economists and market participants became aware of the incidence of the sentiment in the financial markets, reason for Daniel Kahneman and Amos Tversky to find a totally new theory named Behavioral finance that shows the human behavior is not fully rational, explaining this way some persistent anomalies found in the financial markets (Kahneman, Tversky 2000).

If we talk about anomalies in the financial markets we can quote Benoit Mandelbrot who gave in his The (mis)behavior of markets (2004) the following astonishing examples:

- $\quad$ Between 1916 and 2003 according to Gaussian theory it should be no longer than 6 days in which the index oscillation is higher than 4.5\%; there were 366 such days.

- $\quad$ An oscillation of more than 7\% should occur once every 300,000 years; there were 48 such days during this period, 1916 - 2003.

- $\quad$ Events such as Black Monday in 1987, or the Asian crisis of 1997, or the Russian crisis in 1998, as well as the current one with DJIA declines of more than $4 \%$ and consecutive days of huge falls should not have occurred or chances were 1 to billions.

- $\quad$ DJIA declines by $7.7 \%$ in a day = probability of 1 to 50 billion.

- $\quad$ The decline in July 2002 of the DJIA = probability of 1 to 4 trillion.

- $\quad$ October 19, 1987: - 29.2\% decrease of DJIA = probability of 1 out of 10 at power 50 .

The conclusion is the fact the markets are risky, recording extreme amplitude developments which should not be ignored. We can issue the idea of the personality of the markets pointing the fact that prices are not only moved by financial events, but also by the perception of the participants, crating this way a general personality of the market. Another topic to be observed is the evolution pattern of the capital market who gives the impression of predictability through cycles and trends, but all the time a crash surprises the market and severely breaks the continuity of the long-time pattern. Another fact emphasized in Mandelbrot's work is the relativity of time in the financial market saying the time is contracting in moments of volatility and vice versa.

Mandelbrot's 10 affirmations about the markets (The (mis)behavior of markets):

1. Markets are turbulent.

2. Markets are very risky, riskier than the standard theories imagine.

3. Market timing matters greatly; big gains and losses concentrate into small packages of time.

4. In markets, time is flexible.

5. Prices often leap, not glide; that adds to the risk. In markets, time is flexible.

6. Markets in all places and ages work alike.

7. Markets are inherently uncertain, and bubbles are inevitable.

8. Markets are deceptive.

9. Forecasting prices may be perilous, but you can estimate the odds of future volatility.

10. In financial markets, the idea of value has limited value.

\section{The evolution pattern of the Romanian capital markets. Results and discussions.}

The next pictures will reveal some of the veracity of Mandelbrot's affirmation showing 4 examples of extreme risky and volatile market evolution in the Romanian capital market 
in 2008 when the market recorded amazing upside evolutions driven by euphoria and dramatic collapses when the panic took place.

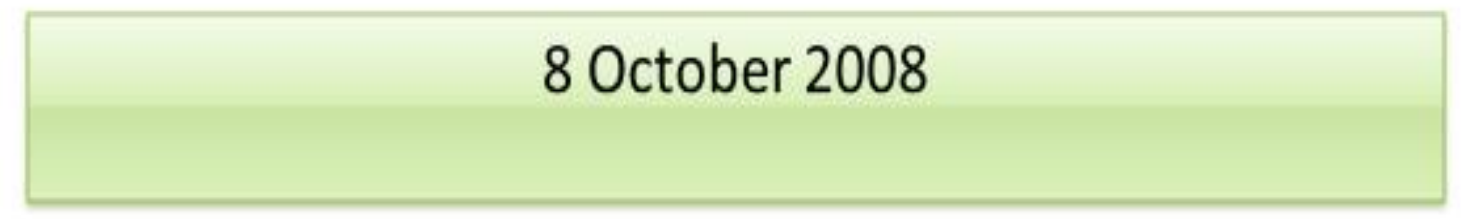

PICBE $\mid 202$

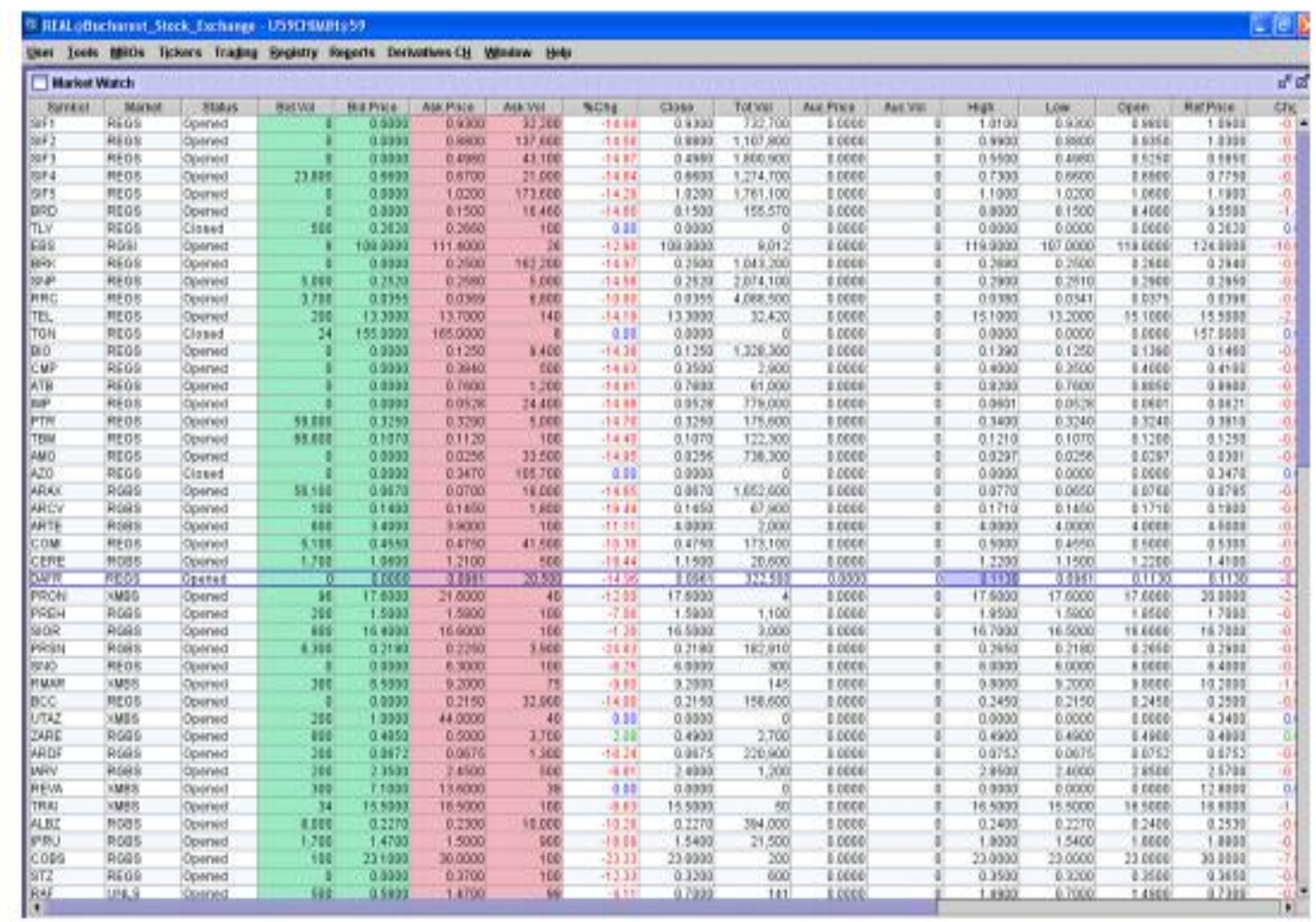

Figure 1. Arena trading platform (Bucharest Stock Exchange) - live quotes on different hectic days: 8 October 2008

Source: BSE. 


\section{October 2008}

PICBE $\mid 203$

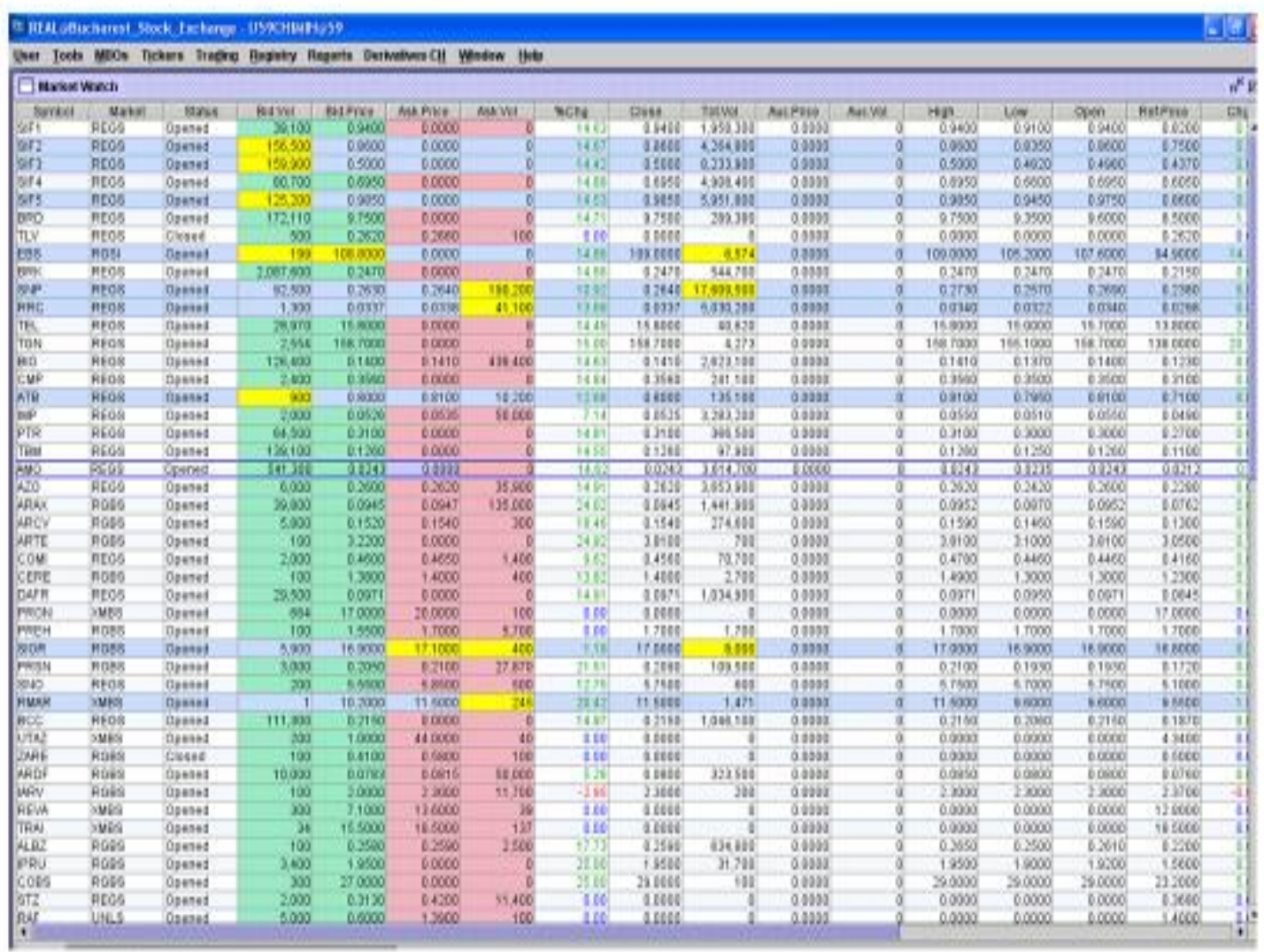

Figure 2. Arena trading platform (Bucharest Stock Exchange) - live quotes on different hectic days: 14 October 2008

Source: BSE. 


\section{October 2008}

PICBE | 204

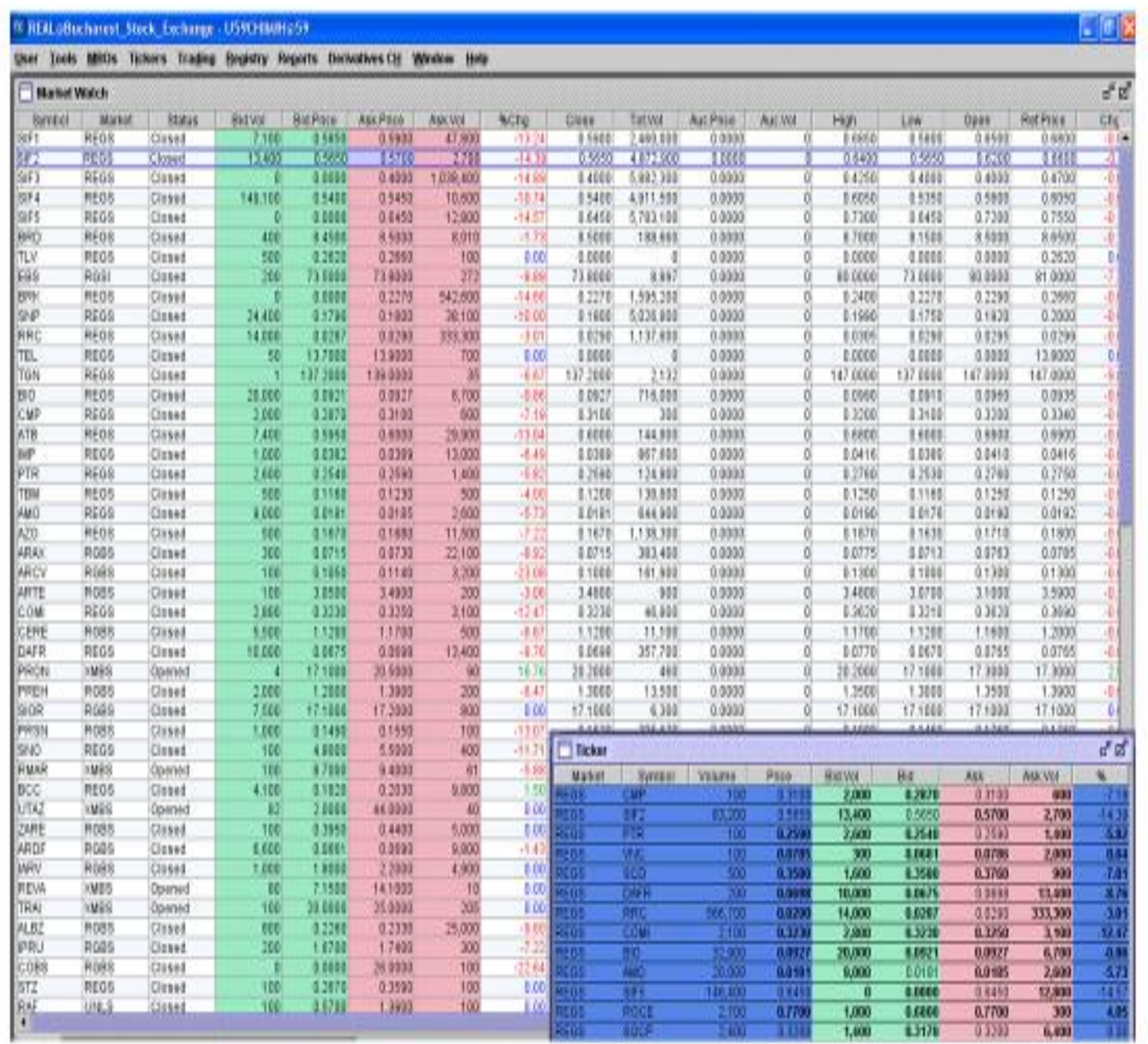

Figure 3. Arena trading platform (Bucharest Stock Exchange) - live quotes on different hectic days: 22 October 2008

Source: BSE. 


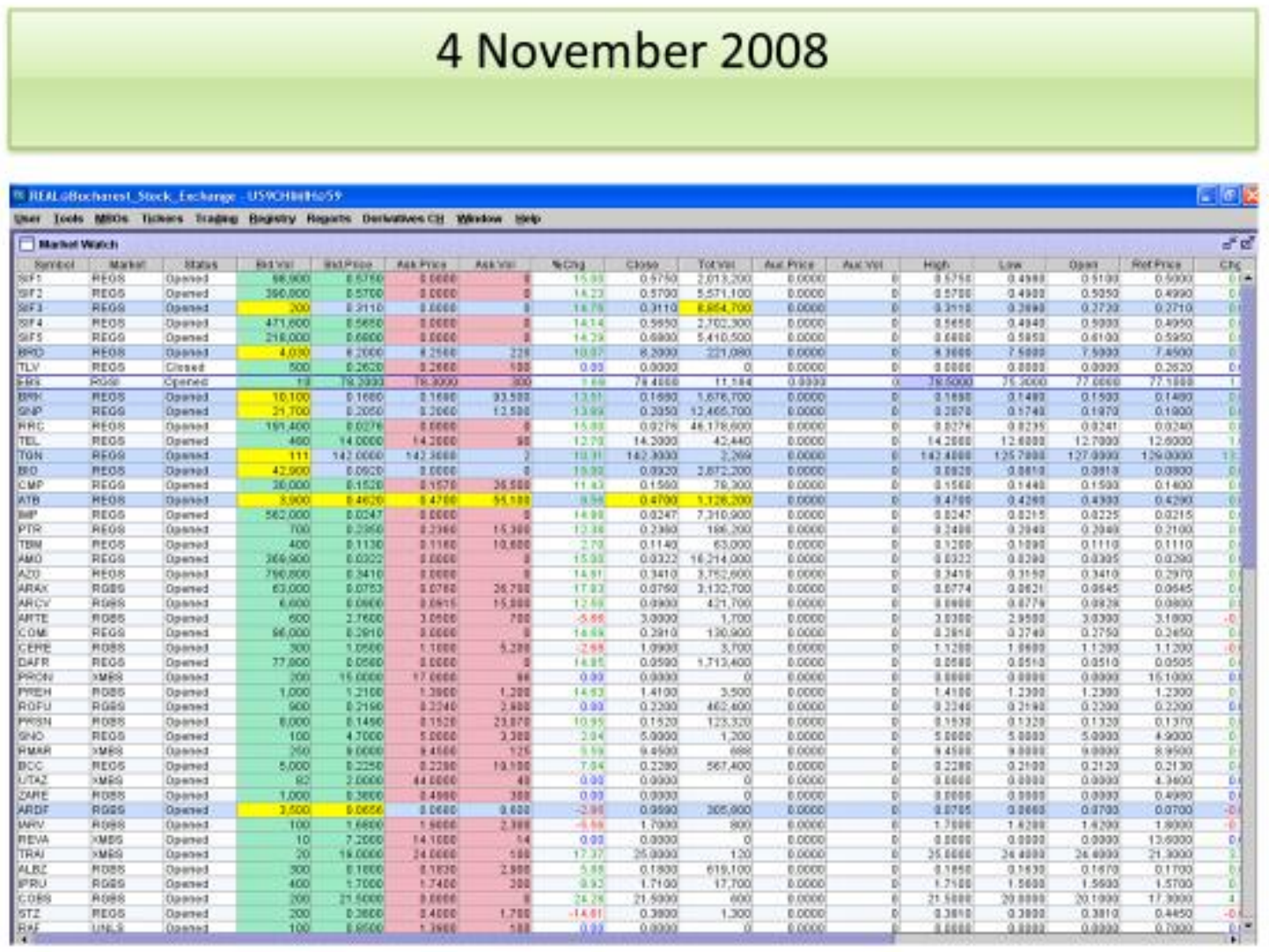

PICBE | 205

Figure 4. Arena trading platform (Bucharest Stock Exchange) - live quotes on different hectic days: 4 November 2008

Source: BSE.

The Romanian capital market recorded a very extreme evolution starting with July 2007 and ending with spring of 2009, the financial index going down from a euphoric 96,452 points to no more than 7,666 points in February 2009, as shown in the table below:

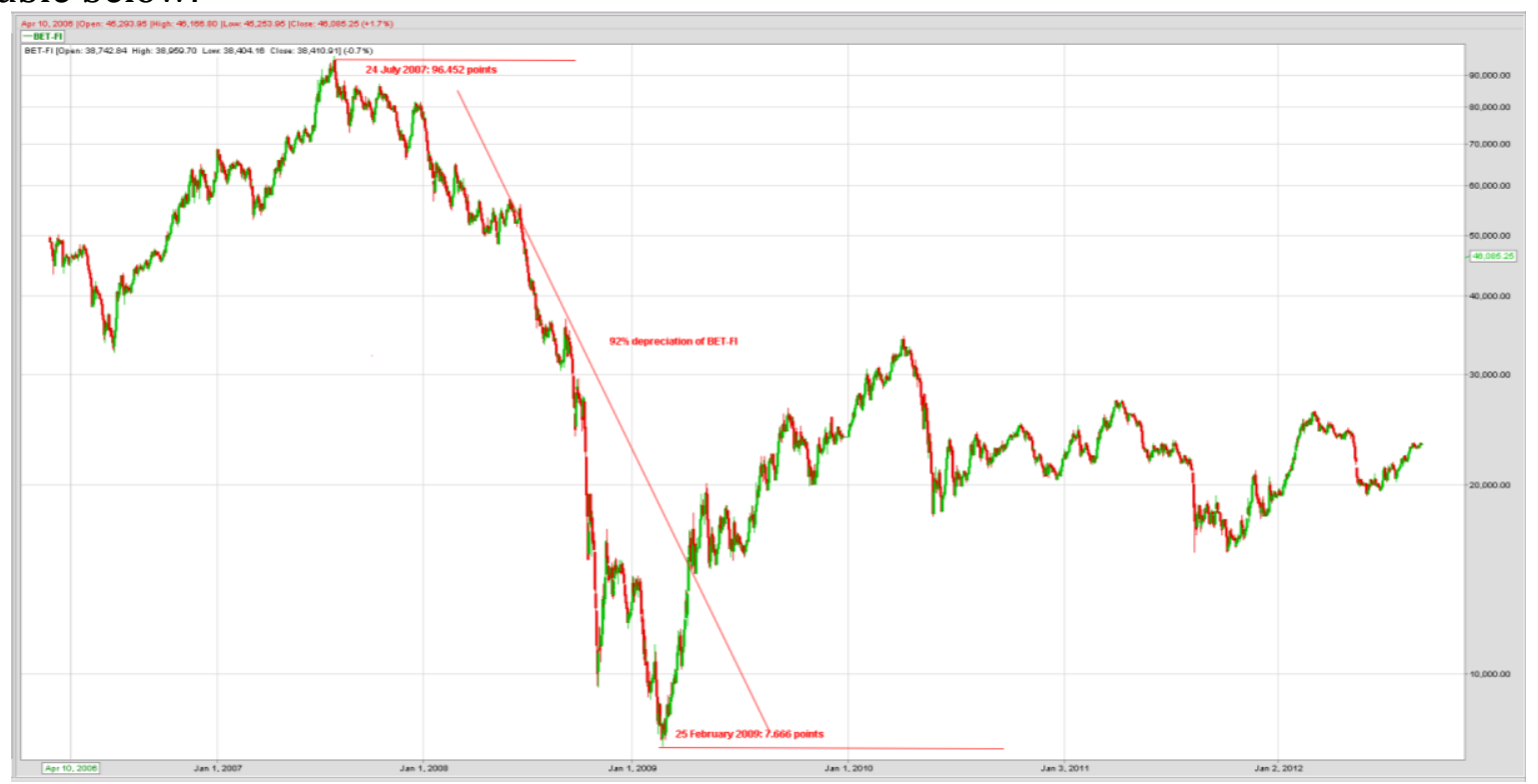

Figure 5. BET-FI Index - Romanian capital market

Source: Author's own research. 
But what could possibly cause such a tremendous move, a 92\% decrease in less than 2 years? There are many facts to describe this speculative bubble followed by the market crash of 2008-2009. With a relative new born capital market in 1995, Romania has entered the European Union in 2007 creating a perfect economic environment for all the companies to expand their activities, to embrace the corporate government, to be more predictable and efficient. This positive and promising climate has attracted numerous foreign investors who have invested in the Romanian economy and capital market. The normal reaction was an appreciation of the values of the listed companies, but in 2007 the bubble burst at the same time with the real estate market and the whole economy in general. It was a hard landing for the economy, the first explicit one Romania had experienced after the communist regime. What has started as a subprime crisis in US in 2007 influenced the climate and sentiment in the Romanian capital market as well, leading to a fast selling process from all the investors categories. In this respect the Romanian capital market was a clear example of euphoria and crisis and nevertheless showed once again that capital markets can be very dangerous if you don't follow the rules and act only by sentiment and wishful thinking. The ingredients who made possible the creation of this bubble was the group mentality, the irrational exuberance and the over liquidity existence in the market. Participants in the market could not agree at that time that an imminent depreciation of the market may appear, they put aside anyone who dared to express a different opinion beside the positive evolution of the market, while the foreigners kept supplying the market with amounts of money big enough to create over demand for shares considering the relative small and illiquid market dimension.

Looking back in time we can find dozens of examples of bubbles and crashes, the first ever described being the notorious case of tulip mania in $17^{\text {th }}$ century. The journalist Charles Mackay was the first to write about it in his book Extraordinary Popular Delusions and the Madness of Crowds, written in 1841.

Nowadays the bubbles are getting even fasters being in a strong relation with the development of different areas of the global economy. The beginning of the millennium was marked by the explosion of the tech bubble, when Nasdaq who was mostly composed by companies in this area overpassed S\&P 500 as it can be easily seen in the image below.

US Share Price Indices

3 January $1995=100$

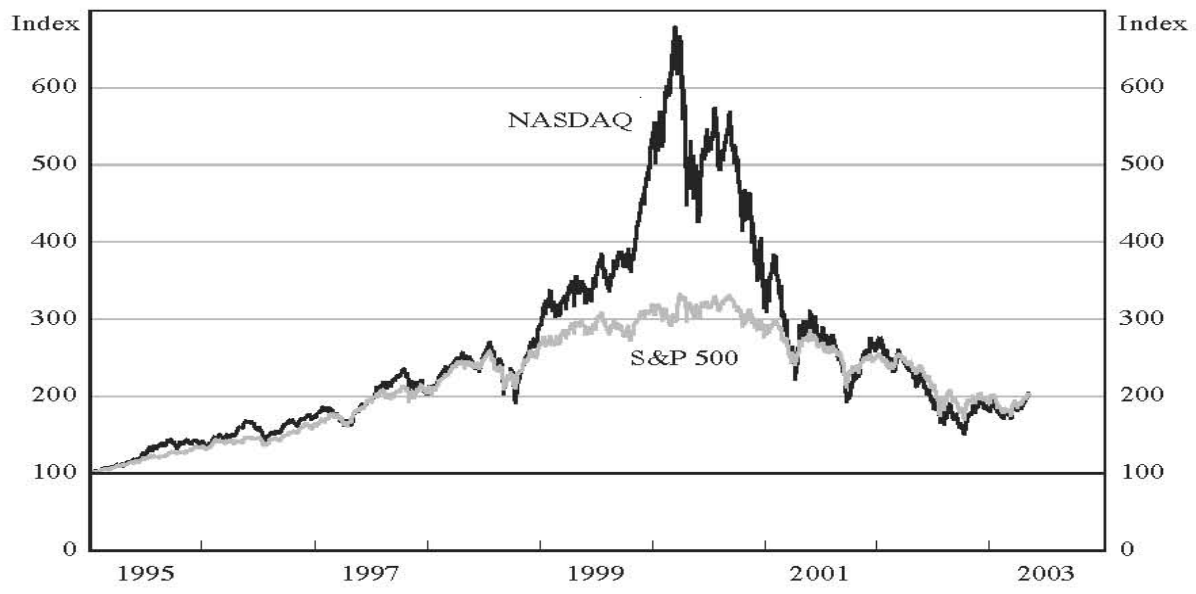

Figure 6. Dot-com bubble (S\&P500 vs Nasdaq)

Source: Author's own research. 
Well-known companies such as Yahoo or e-Digital recorded amazing evolutions from a few dollars per share to tens or even hundreds of dollars per share and ended the cycle at same small capitalization or even bankruptcy.

A picture who entirely describes the creation, the evolution and finally the burst of a bubble-crash event can be seen bellow, comprising all the sentiments who drive the investors in this volatile world of the capital markets. If the first part of this cycle is easy to ride and all the investors consider is something normal and rewardable for their inspired placements, the downtrend in the sentiment trend is very painful since the investor usually tries to convince itself he is not wrong, he denies the reality and generally capitulates at the end of the whole cycle. The capitulation is the best moment for the professionals to step into the market and put aside cheap shares for the next upward cycle.

Fear, Hope, and Greed

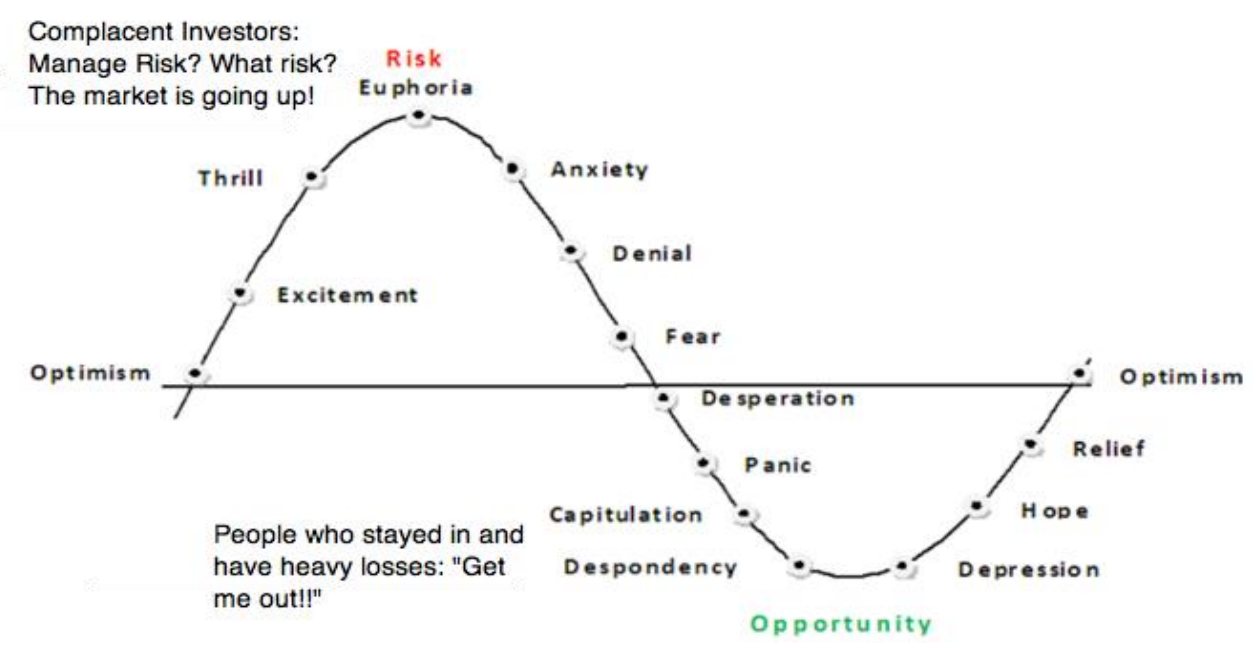

Figure 7. Cycle of investor sentiment

Source: Author's own research.

\section{Conclusions}

The markets will continue to have cyclical patterns as long the human beings are behind desks and make decisions regarding shares and investments. Basically, all this volatility has most of the time a common culprit: the sentiment. Neoclassical finance theory does not say anything about investor sentiment because market valuation is based only on fundamentals. Sentiment, as a risk factor, has been rejected because the informationefficient financial markets eliminates irrational participants. However, the frequent occurrence of mistaken valuation of securities prices, untapped opportunities for arbitrage which are reflected in closed-ended discounts, sub-valuation of initial public offerings, weekend effect, January anomaly, financial crises, etc. have generated the concern of some theorists to discover explanations about these market anomalies. Despite this evidence, the researchers have not agreed on a common definition of the sentiment of investors who feel their presence directly or indirectly in their trading activities on the market, reason to find a whole range of definitions in the literature.

And finally, as a generally valid remark, the definitions above do not provide any explanation if the sentiments contain information about the value of an action or about the stock market. Theoretically, emotions are triggered by the availability of information, general knowledge, personal imagination or ability to comprehend. In the 
psychological sense, cognitively triggered feelings are the result of an interpretation and explanation of an event by a person. Investors' feelings, under the notion of emotion, always represent expectations about the future evolution of the returns on the shares or the market as a whole.

Even if you are a beginner or an expert the sentiment and the way you judge it will interfere in your decision process and positively or negatively will impact the outcome. The biggest challenge is to understand the market sentiment and try to take advantage of it. Technical analysis and fundamental analysis are extraordinary useful tools to navigate in this volatile world of capital markets, especially when markets transform themselves into promising paradises (bubbles) or unpleasant worlds of hard decisions (market crashes).

\section{References}

Abarbanell, J. S., Bushee, B. J. (1997), Fundamental Analysis, Future Earnings, and Stock Prices, Journal of Accounting Research, 35 (1), 1-24.

Baker, H., K., Nofsinger, J., R. editors (2010), Behavioral Finance, Investors, Corporations, and Markets, The Robert W. Kolb Series in Finance, John Wiley \& Sons, Inc., Hoboken, New Jersey.

Bodie, Z., Kane, A., Marcus, A. J. (2014), Investments, 10th Edition, McGraw-Hill Education.

Diermeier, J. J., Ibbotson, R. G., Siege, L. B., (1984), The demand for capital market returns: A new equilibrium theory, Financial Analysts Journal, 40 (2), 74-80.

Fama, E., F. (1965), The Behavior of Stock Market Prices, The Journal of Business, 38 (1), 34-105.

Glickstein, D. A., Wubbels, R. E. (1983), Dow Theory is alive and well! The Journal of Portfolio Management, 9 (3), 28-32.

Helfert, E. A. (2001), Financial analysis tools and techniques: a guide for managers, 10th Edition, New York, McGraw- Hill.

Kahneman, D., Tversky, A. (2000), Choices, Values, and Frames, Cambridge University Press.

Keynes, J. M. (2008), The General Theory of Employment, Interest and Money, Atlantic Publishers\&Distributors (P) LTD.

Mandelbrot, B., Hudson, R., L. (2004), The (mis)behavior of markets, Basic Books, NewYork.

Markowitz, H., M. (1991), Foundations of Portfolio Theory, The Journal of Finance, 46 (2), 469-477.

Murphy, J. (1999), Technical Analysis of the Financial Markets, New York: New York Institute of Finance.

Reilly, F. K., Brown, K.C. (2012), Investment Analysis and Portfolio Management 10th Edition, South-Western Cengage Learning

Schumpeter, J. A. (2006), History of Economic Analysis, Routledge's collection, Taylor \& Francis e-Library.

Sharpe, W., F. (1964), Capital Asset Prices: A Theory 0f Market Equilibrium under Conditions of Risk, The Journal of Finance, 19 (3), 425-442.

Smith, A. (1998), The Wealth of Nations, The Electric Book Co

Zaloom, C. (2007) The Discipline of Speculators, in Global Assemblages: Technology, Politics, and Ethics as Anthropological Problems (eds A. Ong and S. J. Collier), Blackwell Publishing Ltd, Oxford, UK. 